\title{
Study on the Network-Based English Phonetics Teaching Mode for English-Major Students
}

\author{
https://doi.org/10.3991/ijet.v14i05.8277 \\ Yanwei Wang $\left({ }^{\bowtie}\right)$, Haisen Zhou \\ Anhui Institute of Information Technology, Wuhu, China \\ ywwang3@iflytek.com
}

\begin{abstract}
With the development of Information Technology, internet is accessible to all, especially to the students. Based on the network, English teaching is changing greatly, which is not simply with textbooks, chalk and blackboard, but with multimedia, various apps and other tools. As to study the network-based English phonetics teaching mode for English-major students, the background of the application, the steps of the network-based teaching mode and the theoretical basis are introduced firstly. By selecting college Englishmajor students of 2017 in Anhui Institute of Information Technology as the object of the teaching experiment, the paper describes the investigation and analyzes the data, which shows that the students learning based on the network have better pronunciation in English than those learning in the traditional mode. Thus, the author suggests that teachers use the network-based teaching mode to improve the effectiveness of teaching and learning.
\end{abstract}

Keywords-Network-based teaching mode, phonetics, teaching experiment

\section{Introduction}

With the development of Information Technology, internet is accessible to all, especially to the students. Based on the network, English teaching is changing greatly, which is not simply with textbooks, chalk and blackboard, but with multimedia, various apps and other digital tools. For English-major students, the network-based teaching mode is playing a more important role, especially for the teaching of English phonetics.

In terms of nature and function, language is a system of code combining sound and meaning with speech sound as the material shell, vocabulary as the building block and grammar as the structure law [1]. Teaching of English-major students inevitably involves the teaching of phonetics. The wide use of multimedia technology has changed the situation of "dumb English" teaching which stresses grammar more than pronunciation. With the traditional class teaching, students are passive to listen and the teachers are teaching orally in class [2]. However, the limitation of teachers' inaccuracy of pronunciation leads to the students' errors in pronunciation. Moreover, the students have less time to be corrected in time. The positive effect of computer-aided technology, multimedia-aided teaching technology and the artificial intelligence-aided 
teaching technique used in English teaching has been verified by relevant scholars [3], but a number of researchers are still reforming and applying the network-based English teaching mode. Under the use of Information Technology, the trend of reforming in English teaching mode is inevitable to happen. The creation of the teaching mode is one of the ways to the reform of English teaching [4].

The network-based English phonetics-teaching mode for English-major students can help the students learning better in English pronunciation than those learning in the traditional mode. Thus, the paper studies the steps of the network-based teaching mode, the effectiveness of the network-based teaching mode, and selects the college English-major students of 2017 in Anhui Institute of Information Technology as the object of the teaching experiment to show the significance of the model.

\section{Network-Based Teaching Mode}

Teaching mode is the theme of education. Network-based teaching mode which focuses on net learning is the reform to the traditional teaching mode. With the advantages, it is possible to achieve more effectiveness in teaching.

\subsection{Theoretical basis of network-based teaching mode}

Constructivism is the theory proposed by cognitive psychologist Piaget which believed that the teaching should be centered on the students. Students are becoming the body of the class instead of passive indoctrinators of knowledge. Teachers need to change to counsel students, to help and instruct the learning instead of teaching knowledge [5].

For constructivism, in the process of learning, the students' learning resources have been enlarged beyond textbooks, the relationship involved in the teaching has been changed from one-way to mufti-directional, interaction, interdependence, interconversion, teacher-student interaction, student-student interaction, and humancomputer interaction [6].

Obviously, the network-based English phonetics teaching mode provides an environment conforming to the constructivism theory and taking students as the center [7].

\subsection{Advantages of network-based teaching mode}

As for the network-based English phonetics teaching mode, it is still under debate over its advantages and disadvantages. With the shortcomings of lacking in humanization, in the students' self-discipline, and in the limitation of the courseware, we still see a list of advantages of network-based teaching mode. Here the author cites four main advantages.

High learning interests: Interest is the most important teacher for the students in learning. However, in the traditional class, the interest is difficult to get from the boring and dull contents taught by the teachers through blackboard. The learning environment in the new generation can benefit from argumentation with advanced tech- 
nologies [8]. The network-based English phonetics teaching mode means the use of multimedia technology which combines text, images, sounds and videos in order to establish logical relationship and human-computer interaction [9]. The new teaching mode provides more vivid pictures and voices. It arouses the interest of the students in learning English.

Abundant learning resources: One of the advantages of the net-based learning is its abundant resources [10]. By contrasting the traditional teaching mode, the network-based teaching mode can provide resources both at home and abroad. The most related ancient poems in English, the most distant movies in Hollywood, and the latest news in the world are presented to the students. Students thus have opportunities to access unlimited knowledge and information.

Autonomous learning habits: Dickson holds that autonomous learning is both a learning attitude and an independent learning ability [11]. The network-based teaching mode has no limitation in time and space. The teachers can give the different assignments to the students according to the level of the students. In the traditional teaching mode, the students get the same assignment. The students above the level may feel the assignment too easy, whereas the students below the level may feel the assignment a little difficult. In the network-based teaching mode, the students have the assignments to their level, so they can develop an autonomous learning habit.

More native pronunciations: Pronunciation is more important for English learners especially for English-major students. The English-major students use English in their future job. Therefore, the one who has a more accurate pronunciation gets more opportunities to improve in his career. Network-based teaching mode can provide videos, movies with native speakers for the students to improve their language competence. Krashen holds that only when the language input reaches a certain amount can the language output be ensured [12]. Thus, with the exposure to native speakers through network-based teaching mode gradually, the students can improve their language skills.

\subsection{Application of network-based English phonetics teaching mode}

With the purpose of improving the level of pronunciation of English for Englishmajor students, the author designs the network-based English phonetics teaching mode which is to be illustrated as follows. The author defines the new teaching mode by three stages, before class, in class and after class.

During the period before class, the teacher gives assignments in advance to let the students finish, such as the introduction of English, the theory of phonetics and the rules in reading English. The assignments cannot be finished without internet. The students need to be on line and find the information about assignments. With the help of the net, students are easy to get more information. And before class, after searching for the information needed, the students still need to summarize the information and put the important information on PowerPoint, which will be sent to the teachers by QQ or email. This is the first step of the mode and the important part of the course design as showed in Figure 1. 


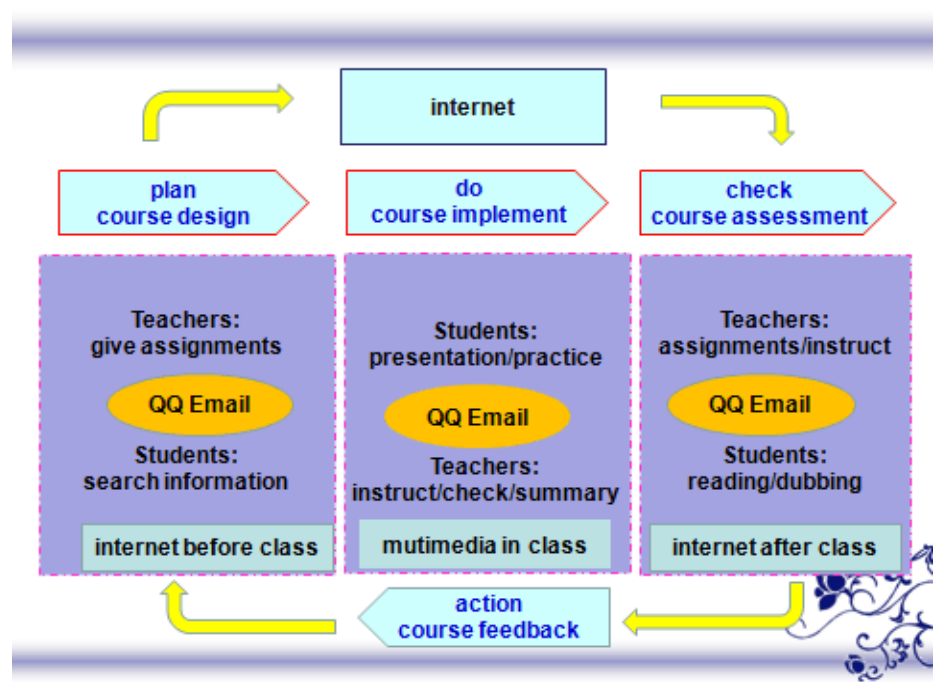

Fig. 1. The network-based English phonetics teaching mode

During the period in class in Figure 1, the students need to present the PowerPoint. to the teacher and other students. With multimedia, all including the students and the teacher can see the homework done by the students clearly. Thus, the students are the focal point in class to show their work, and what the teacher needs to do is to instruct the students and give comments. After giving the summary of the rules in reading English, the teacher can let the students practice more and to correct the inaccurate pronunciation made by the students. Teacher is no longer the center of the class, but the controller of the class, not the teller all the time but the instructor of the class. The students also actively participate in the activities in class, not the passive listeners any longer. Together with the sound, pictures, and videos, the network-based teaching mode can arouse the interest of the students, which makes an effective class. This is the second step of the mode and the part of the course implemented.

During the period after class in Figure 1, the students are required to review the lesson. However, it is different from the traditional reviewing. The tasks for the students is to read and dub the movies and speeches. The students need to finish the tasks on line with the Dubbing app. After dubbing online the students can send it to the teacher through QQ or Email. The teacher can listen to the dubbing made by the students without the limitation of the class period. The students can get the teacher's instruction after class. This is the third step of the mode and the part of course assessment.

Through the tasks, the teacher can get feedback of the acceptance of the knowledge, the improvement of the students, and the inaccurate pronunciation, all of which can give the information for the teachers to design the class. The new teaching mode is also an example of PDCA, which will enable the teacher to improve the ability of teaching. 


\section{Experiment Design and Data Analysis}

With the development of the society and the rapid growth of international integration higher education meets the challenges greatly. For college teachers, we need to improve to meet the requirements brought by the rapid development [13]. We should not only use the traditional teaching mode, but also use the network-based teaching mode to teach the students. Thus, the assessment of the network-based teaching mode is used to be designed in Anhui Institute of Information Technology. The author implements the experiment by questionnaire investigations and data analysis to show the hypothesis that the network-based teaching mode can benefit students better than the traditional teaching mode.

\subsection{Experiment objects}

The experiment takes the English-major college students of 2017 from Anhui Institute of Information Technology as objects. The total number of the students are 78 who are in two classes. Table 1 is the information of background and learning time. Table 2 is the one-way analysis of variance on the average entrance score.

Table 1. Basic information between the experiment class and the control class

\begin{tabular}{|l|c|c|c|c|}
\hline \multicolumn{1}{|c|}{ Class } & No. & Male/female (\%) & Average entrance score & $\begin{array}{c}\text { Weekly extracurricular speak- } \\
\text { ing and reading time(hour) }\end{array}$ \\
\hline Experiment class & 38 & $13.2 / 86.8$ & 105.5 & 1.3 \\
\hline Control class & 40 & $10.0 / 90.0$ & 106.7 & 1.5 \\
\hline Total & 78 & $11.5 / 88.5$ & 106.1 & 1.4 \\
\hline
\end{tabular}

From Table 1 we can see that the two classes are similar in some ways. The size of the class, the average entrance score (total of 150) and the weekly extracurricular speaking and reading time are similar to each other for the two classes.

Table 2. One-way analysis of variance (ANOVA) on the average entrance score

\begin{tabular}{|l|c|c|c|c|c|}
\hline & Sum of Squares & df & Mean Square & F & P-value \\
\hline Between groups & 26.844 & 1 & 26.844 & & \multirow{3}{*}{0.225} \\
\cline { 1 - 4 } Within groups & 9047.874 & 76 & 119.051 & 0.636 \\
\hline Total & 9074.718 & 77 & & & \\
\hline
\end{tabular}

To get the one-way ANOVA on the average entrance score, the statistical software (SPSS) is used. From Table 2, we can see that $\mathrm{F}=0.225<1, \mathrm{P}=0.636>0.05$, which shows that little obvious differences are existed in the two classes. And for this, we can have the experiment continued and look forward to the result of significant differences. 


\subsection{Experiment process}

The learning requirements for the experiment class and the control class are different. For the experiment class, the students are assigned to preview the lessons on the net, including watching the videos of English pronunciation, seeing the film of English version and dubbing the cartoons and TV plays in English. After finishing the assignments, the students should send the dubbing to the teachers by QQ or emails. In the class, the teacher delivers the theory in English pronunciation, let the students practice the pronunciation, and correct the incorrect pronunciation of the students. The teacher can also use the net in the class through multimedia to let the students dub the native speakers by groups. Thus, the teacher is the tutor in the class to instruct the pronunciation of the students, and the students are the center to do the exercises and practice of the pronunciation. After class, the students are asked to review the lessons on net and finish the tasks assigned by the teachers through emails or BBS.

The following figures give the examples of the experiment class teaching based on the net. Figure 2 is the assignments checking. Figure 3 is the new points in learning the lessons.

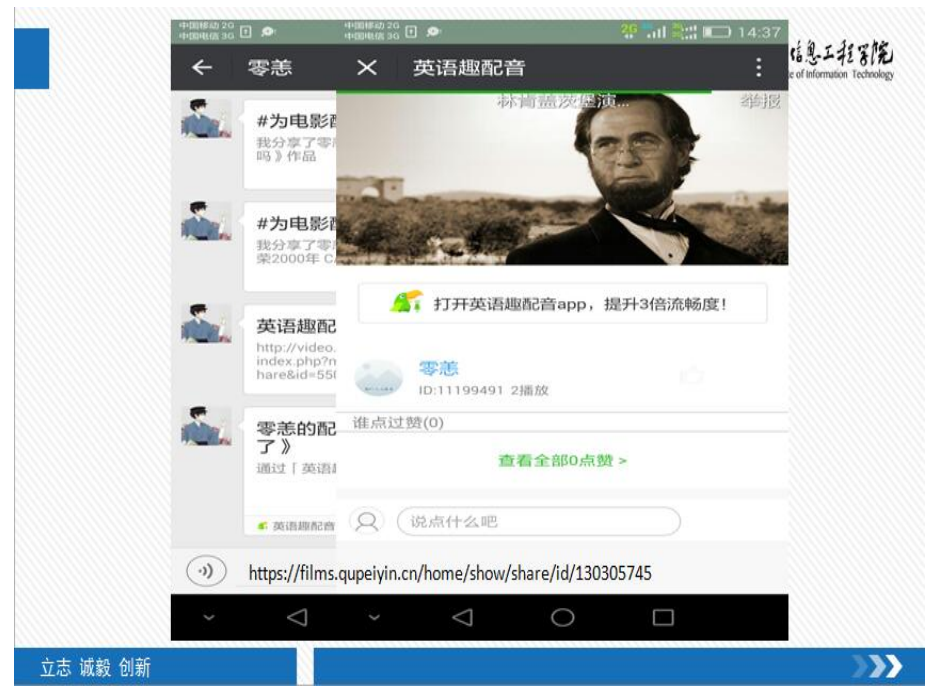

Fig. 2. Dubbing the short video

In Figure 2, we can see that the teacher can check the assignments of dubbing through multimedia by clicking the start button and the students can dub the short video. This use of video can stimulate the students' interests in learning English phonetics, and through dubbing and imitating the native speakers, the students can speak English more effectively. After checking the assignments, the teacher uses a short time to illustrate the rules in pronunciation of the new knowledge, which is shown in Figure 3. 


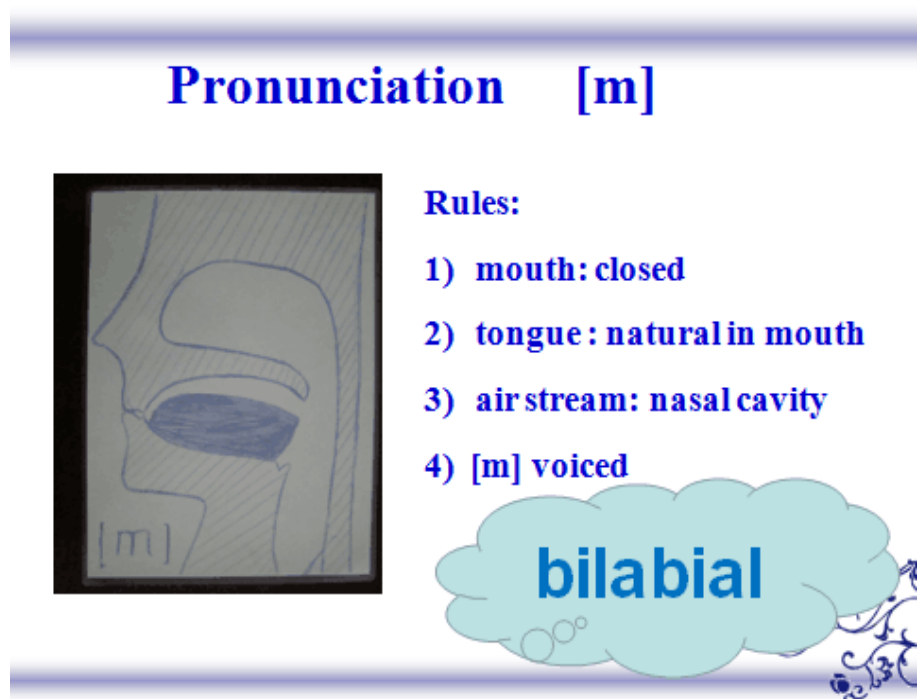

Fig. 3. New point of the lesson

In Figure 3, we can see that the consonant [m] is taught. In the PowerPoint, the teacher lists the rules in pronunciation and the classification of $[\mathrm{m}]$. With the picture and the rules, the students can understand the pronunciation well and pronounce it correctly. After that the students will have more opportunity to practice the newly acquired knowledge.

On the other hand, the students in the control class have their lessons in the traditional classroom, with the teachers delivering lessons through textbooks, blackboard and chalk. The assignments done by the students cannot monitored by the teachers after class, but only in the class. The teachers check the reading for the pronunciation homework in the class and correct them within the short class period.

Meanwhile, questionnaires and investigation have been used to testify the attitude and learning autonomy of using network-based teaching mode for the experiment class at both the beginning and the end of the semester in Anhui Institute of Information Technology. The investigations are aimed to measure ordinal variables to measure attitudes [14]. At the end of the semester, the same examination of reading phonetic symbols, words, phrases, sentences and paragraphs is to make for all the students to testify whether the experiment class do better than the control class. Moreover, a statistical software (SPSS) is used to collect and summarize data efficiently to get meaningful information about the data and supporting the performance of statistical operations to enhance the validity of the collected data [15].

\subsection{Experiment result}

In order to find the results of network-based teaching mode, the questionnaire is used. There are 6 questions. Questions 1 to 3 are used to know the purpose, the average time and the study scope of the students for using the net, which aims to get the 
information of students' learning autonomy. Questions 4 to 6 are used to know the acceptance, the effectiveness and the recommendation of net-learning, which aims to get the information of students' attitude toward network-based teaching mode. 38 questionnaires are sent and collected, which are all valid. Table 3 is the result of Questions 1 to 3. Table 4 is the result of Questions 4 to 6 .

Table 3. Questionnaire for the information of students' learning autonomy

\begin{tabular}{|l|c|c|c|c|c|c|c|c|c|}
\hline \multirow{3}{*}{ Item } & \multicolumn{3}{|c|}{$\begin{array}{c}\text { Purpose of } \\
\text { using net(\%) }\end{array}$} & \multicolumn{3}{c|}{$\begin{array}{c}\text { Average time on line per } \\
\text { week (\%) }\end{array}$} & \multicolumn{3}{c|}{$\begin{array}{c}\text { Scope of study } \\
\text { on line(\%) }\end{array}$} \\
\cline { 2 - 10 } & study & amuse & others & zero & 5-8hrs & $\begin{array}{c}\text { 8hrs } \\
\text { more }\end{array}$ & English & Chinese & others \\
\hline Beginning & 21.1 & 55.3 & 23.6 & 13.2 & 63.2 & 23.6 & 30.4 & 60.5 & 21.1 \\
\hline End & 65.8 & 18.4 & 15.8 & 0.0 & 71.1 & 28.9 & 84.2 & 10.5 & 5.3 \\
\hline
\end{tabular}

From Table 3 we can see that at the beginning of the semester, most of the students use net for amusement and only $21.1 \%$ of the students use net to study. However, at the end of the semester, most of the students use net to learn which is $65.8 \%$. The purpose of learning on net is increased by $44.7 \%$. As to the average time of the students at the beginning, $13.2 \%$ of the students do not use net, but at the end of the semester, there are no one who does not use net. This is the significant change of using the new mode for the students. Of course, for the learning subject at the end of the semester, the students spend more on English partly because they are English majors.

Table 4. Questionnaire for the attitudes of students' net learning

\begin{tabular}{|l|c|c|c|c|c|c|c|c|c|}
\hline \multirow{2}{*}{ Item } & \multicolumn{3}{|c|}{ Acceptance (\%) } & \multicolumn{3}{c|}{ Effectiveness (\%) } & \multicolumn{3}{c|}{ Recommendation (\%) } \\
\cline { 2 - 10 } & totally & agree & disagree & high & med. & low & strongly & willing & unwilling \\
\hline Beginning & 15.8 & 73.7 & 10.5 & 13.2 & 57.9 & 28.9 & 7.9 & 47.4 & 44.7 \\
\hline End & 26.3 & 71.1 & 2.6 & 26.3 & 65.8 & 7.9 & 23.6 & 63.2 & 13.2 \\
\hline
\end{tabular}

From Table 4 we can see the result of the students' attitude toward the networkbased teaching mode. At the beginning only $15.8 \%$ of the students totally accept the net learning and $10.5 \%$ of the students do not accept it. However at the end of the semester, the total acceptance is increased by $10.5 \%$ and the nonacceptance decreased by $7.9 \%$. From the changes in the percentage we can see most of the students accept the new mode of net learning. As for the effectiveness of net learning, at the end of the semester, the percentage of the students who think that net learning has high effectiveness is increased by $13.1 \%$, whereas, the percentage of the students who think that net learning has low effectiveness is decreased by $21.0 \%$. From the change, we can see that the students can benefit immensely from net learning, thus $86.8 \%$ of the students are willing or strongly willing to recommend the use of net learning.

We still see some of the students do not accept and are unwilling to recommend net learning to their friends. The author asks about the reasons. From the investigation, the author observes that they lack searching skills on the net, which waste their time 
in learning. Thus, the author believes the instruction of using net effectively is to be taught to the students.

Table 5. The scores of final examination

\begin{tabular}{|l|c|c|c|c|}
\hline \multicolumn{1}{|c|}{ Class } & No. & Highest score & Lowest score & Average score \\
\hline Experiment class & 38 & 90 & 53 & 73.8 \\
\hline Control class & 40 & 93 & 48 & 69.3 \\
\hline Total & 78 & 93 & 48 & 71.5 \\
\hline
\end{tabular}

After analyzing the students' attitude and the learning habits, the author aims to know whether the network-based teaching mode stimulates the students and whether the students' reading ability is improved. Thus, the same examination is to be taken by all the students. From Table 5 we can see that at the end of the semester, the scores of the experiment class and the control class is different. Although there is a student who gets the highest score 93 is in the control class, the average score of the examination of the experiment class which is 73.8 is higher than the control class which is 69.3. That is to show that network-based teaching mode can provide effectiveness in English phonetics learning for English-major students.

Table 6. One-way analysis of variance (ANOVA) on the average final score

\begin{tabular}{|l|c|c|c|c|c|}
\hline \multicolumn{1}{|c|}{ Class } & Sum of Squares & df & Mean Square & F & P-value \\
\cline { 1 - 4 } Between groups & 392.771 & 1 & 392.771 & \multirow{2}{*}{4.002} & \multirow{2}{*}{0.049} \\
\cline { 1 - 4 } Within groups & 7458.716 & 76 & 98.141 & & \\
\hline Total & 7851.487 & 77 & & & \\
\hline
\end{tabular}

To see whether there is significant differences between the control class and the experiment class, the ANOVA on the average final score is to be analyzed. From Table 6 , we can see that $\mathrm{F}=4.002>1$, and $\mathrm{P}=0.049<0.05$, which shows that obvious differences are existed in the two classes. That is to show that networked based English phonetics teaching mode can bring effective studying.

\section{Conclusion}

Through the experiment and data analysis, we find that the network-based teaching mode can benefit students better than the traditional teaching mode. It helps the English-major students to have access to more learning resources, to speak English in a more effective manner, and to develop the habit of autonomous learning. Meanwhile it helps the teacher to have a reform in English phonetics teaching and spare more time to dedicate to research. 


\section{$5 \quad$ Acknowledgement}

The work was supported by the Research Project of Teaching Reform in Higher Education in Anhui Province. (No. 2016jxtd056)

\section{References}

[1] Yang, Z., Wang, C., Feng, L., Li, S., Tao, S. (2016). Unsuccessful letter-sound integration in English reading by native Chinese speakers: Evidence from an event related potentials study. Science Bulletin, 61(24): 1855-1864. https://doi.org/10.1007/s11434-016-1078-y

[2] Wik, P., Hjalmarsson, A. (2009). Embodied conversational agents in computer assisted language learning. Speech Communication, 51(10): 1024-1037. https://doi.org/10.1016/j.s pecom.2009.05.006

[3] Liu. (2013). The application of computer technology in music education. International Journal of Technology Management, 88-90.

[4] Diaz, L.C., Algorry, A., Eschoyez, M., Barto, C. (2013). Actions towards the application of intelligent systems in computer education. IEEE Latin America Transactions, 11(1): 591-595. https://doi.org/10.1109/TLA.2013.6502866

[5] Coupal, L.V. (2004). Constructivist learning theory and human capital theory: Shifting political and educational frameworks for teachers' ict professional development. British Journal of Educational Technology, 35(5): 587-596. https://doi.org/10.1111/j.00071013.2004.00415.X

[6] Zhao, Y., Zhang, M., Wang, S., Chen, Y. (2005). Exploring constructivist learning theory and course visualization on computer graphics. Lecture Notes in Computer Science, 3483, 1-9. https://doi.org/10.1007/11424925 1

[7] Yu Limin, Guo Hongjie, "On the Application of the Internet in Foreign Language Learning: A Constructivist Learning Perspective ", Foreign Languaes in Fujian, FLFJ, vol.75, no.1, pp26-29, 2003

[8] Jui-Hung Chen, Han-Bi Chang, "Immersive Learning Environment with Intetrated Interactive Video and Ubiquiitous Technologies", JCIT: Journal of Convergence Information Technology, AICIT, vol.5, no.9, pp. 61-72, 2010 https://doi.org/10.4156/jcit.vol5.issue9.6

[9] Chen Qiaoping, "Research for Influence of Physical Education Multimedia Teching on Sports Motivation of Students", AISS: Advance in Information Sciences and Serice Sciences, AICIT, vol.4, no.16, pp. 14-22, 2012 https://doi.org/10.4156/aiss.vol4.issue16.3

[10] Shi Lin, "A Study of the Ecological Web-based College English Teaching Environment from the Constructive Perspective", Computer-Assisted Foreign Language Education in China, CAFLE, vol.145, no.3, pp. 62-65, 2012

[11] Dickinson, L., Self-instruction in Language Learning, Cambridge University Press, Cambridge, 1987

[12] Krashen, Stephen D., The input hypothesis, Longman, London, 1985

[13] Grabowski, M. (2014). The role of transnational integration in forming of northeast Asian community. Tectonics, 20(6): 959-975. https://doi.org/10.15611/pn.2014.370.03

[14] Bryman, A. 2006. Integrating quantitative and qualitative research: how is it done? Qualitative Research 6, 97-113. https://doi.org/10.1177/1468794106058877

[15] Stevens, S.S. 1946. On the Theory of Scales of Measurement. Science 103, 677-680. https://doi.org/10.1126/science.103.2684.677 


\section{Authors}

Yanwei Wang is with the Department of Foreign Studies, Anhui Institute of Information Technology, Wuhu 241000, China.

Haisen Zhou is with the Division of Human Resources, Anhui Institute of Information Technology, Wuhu 241000, China.

Article submitted 2018-01-21. Resubmitted 2018-11-19. Final acceptance 2018-11-21. Final version published as submitted by the authors. 